\title{
Prevalence Oncogenic Human Papillomavirus in Cervical Cancer Patients in Riau Province Indonesia
}

\author{
Maya Savira*1,2, Donel Suhaimi ${ }^{3}$, Andani Eka Putra ${ }^{4}$, \\ Yusrawati Yusrawati ${ }^{5}$, Nur Indrawati Lipoeto ${ }^{6}$
}

\begin{abstract}
Background: Cervical cancer is the fourth most deadly cancer in the world, and it is caused by infection of high-risk subtypes of Human PapillomaVirus (HPV) in most cases. The aims of this study were to determine the prevalence oncogenic HPV in cervical cancer patients in Riau Province Indonesia and to determine the clinical manifestation of HPV in cervical cancer patients in Riau Province Indonesia.

Methods: This research was a descriptive study conducted at Arifin Achmad General Hospital Riau from February to August 2018 which aimed to analyze HPV genotype prevalence oncogenic of cervical cancer patients.

Results: This study showed out 86 of 110 women $(78.1 \%)$ were found HPV positive, and the most common genotype of HPV was HPV 16 (38.2\%). The average age of cervical cancer patient was 50 years old, and the average number of parities was 4 times. The majority of participants were married at the age before 20 years $(77.3 \%)$ and had low educational background $(64.5 \%)$. Vaginal bleeding happened in more than half of the participant as major clinical manifestation $(72.7 \%)$, followed by fluor albus (72.7\%), pelvic pain $(60.2 \%)$ and fatigue $(65.9 \%)$.

Conclusions: The most common HPV genotype in Riau Province was HPV type 16 and the most common clinical symptoms of cervical cancer patient were vaginal bleeding, fluor albus, pelvic pain and fatigue.
\end{abstract}

Keywords: Cervical cancer, Clinical manifestations Human Papilomavirus, Human Papilomavirus genotype prevalence.

\section{Introduction}

Cervical cancer is the fourth most malignancies of women in the world. Concerning the epidemiology, it is estimated that there are 569.847 new cases and 311.365 deaths in 2012 (1). If the number of cases continues to increase, it is estimated that by 2025 cervical cancer in the world will reach 20 million new cases (2). The main risk factor for cervical cancer is related to Human Papilloma Virus (HPV) infection in the cervical epithelium (3). The incidence of recurrence and metastasis to other organs is still the main cause of cervical cancer death, although cervical cancer can be cured at an early stage through surgery and chemotherapy (4).

Human Papillomavirus genotypes are sorted

1: Faculty of Medicine, Andalas University, Padang, West Sumatera, Indonesia.

2: Microbiology Department, Faculty of Medicine, Universitas Riau, Pekanbaru, Riau, Indonesia.

3: Obstetry \& Gynecology Department, Faculty of Medicine, Universitas Riau, Arifin Achmad General Hospital, Pekanbaru, Riau, Indonesia.

4: Microbiology Department, Faculty of Medicine, Andalas University, Padang, West Sumatera, Indonesia.

5: Obstetry \& Gynecology Department, Faculty of Medicine, Andalas University, Padang, West Sumatera, Indonesia.

6: Clinical Nutrition Department, Faculty of Medicine, Andalas University, Padang, West Sumatera, Indonesia.

*Corresponding author: Maya Savira; Tel: +62 8126692650; E-mail: mayadonel@yahoo.co.id.

Received: 16 Mar, 2021; Accepted: 18 Apr, 2021 
based on their findings. Alpha-papillomavirus (including all genital papillomaviruses), Betapapillomavirus (which is responsible for epidermo dysplasia verruciformis), and Gamma-papillomaviruses (which are responsible for skin lesions) are three generations of papillomaviridae responsible for significant diseases in humans (5).

It is estimated that $5 \%$ of cancers in humans are caused by Human Papilloma Virus (HPV) infections. Type $16 \mathrm{HPV}$ is a major cause of cervical cancer, with percentage, respectively, $45.5 \%$ in worldwide and 60\% in Indonesia (6). It is reported that $70 \%$ of cervical cancer caused by the infection of oncogenic type of HPV (high risk type) and it is associated with anogenital cancers in men and women, such as cancer of the penis, vulva, vagina, anal, and oropharyngeal cancer (7). Approximately there are 100 different subtypes of HPV with different variations in potency and oncogenic, and which specifically infecting anogenital area are types $16,18,31,33,35,39,45,52,52,56$, 58, 66, and $69 \mathrm{HPV}(8)$.

In study with cervical cancer samples, $99.7 \%$ of cases had deoxyribonucleid acid (DNA) HPV and dominated by high-risk types, namely $16,18,31$, and 45 , this indicates that high-risk HPV plays a role in the development of cervical cancer (9).

Generally, women with adenocarcinoma and adenosquamous carcinoma are HPV type 18, different from HPV type 16 in women with squamous cell carcinoma. To reduce the incidence of cervical cancer in younger women, HPV testing and vaccination can help, especially adenocarcinoma and adenosquamous carcinoma (10).

Several studies have led to the development of vaccines that offer protection against HPV infections. In early stages, cervical cancer is mostly asymptomatic and might be under diagnosed. Late symptoms include abnormal vaginal bleeding, post-coital bleeding, vaginal discharge be likely the most common complaint that makes patient come to medical workers (11). In this study, we aim to analyze HPV genotype prevalence and describe clinical presentation of cervical cancer patient in Riau.

\section{Materials and Methods}

This research was a descriptive design study that analyzed HPV genotypes and clinical presentation of cervical cancer patients conducted from February 2018 to August 2018. The research permit was granted by the ethics committee of the medical faculty of Universitas Riau with the number 089/UN.19.5.1.1.8/UEPKK/2018. An informed written consent was taken from each participant.

In this study, total 110 participants visiting gynecology department at Arifin Achmad General Hospital Riau Province were recruited consecutively, means all subjects who met the inclusion and exclusion criteria were taken as samples. This method was selected because it was not possible to collect large samples at once. The exclusion criteria in the study were inadequate amount and quality of cervical tissue. While the inclusion criteria were women diagnosed or suspected cervical cancer according to physical examination or histopathology, cervical tissue can be taken as a sample and willing to participate in the study by signing informed consent sheet.

Participants who were enrolled in this study were asked to fill out a questionnaire containing questions about identity/characteristics of patients, clinical complaints and examinations that have been undertaken. Hence, each participant's cervical tissues were taken as a sample for further laboratory tests. DNA is extracted from cervical tissue biopsies with a biopsy punch technique then DNA is extracted from cervical tissue biopsies using purelink Genomic DNA isolation kits (Invitrogen). The working procedure is in accordance with the protocol recommended by the manufacturer.

HPV detection was carried out using DNA amplification. MY/GP primer used is cgtccacaagagggaatactgatc for forward and gcaccagggatcataactaatgg for reverse. The total volume of PCR mixture is $50 \mathrm{ml}$ consisting of 0.5 to $20.0 \mathrm{ml}$ of DNA, $50 \mathrm{mMTris}-\mathrm{HCl}(\mathrm{pH}$ 8.4), $10 \mathrm{mM} \mathrm{KCl}, 2.0 \mathrm{mM} \mathrm{MgCl} 2.1 \%$ bmercaptoethanol, $0.05 \%$ bovine serum albumin, $0.2 \mathrm{mM}$ (each) deoxynucleoside triphosphate, 20 pmol from each primer, and 2.5 
$\mathrm{U}$ of Taq polymerase (Boehringer Mannheim). The PCR program consists of $94{ }^{\circ} \mathrm{C}$ for $5 \mathrm{~min}$, followed by 40 amplification cycles consisting of $94{ }^{\circ} \mathrm{C}$ for $30 \mathrm{~s}, 45^{\circ} \mathrm{C}$ for $60 \mathrm{~s}$, and $72{ }^{\circ} \mathrm{C}$ for 60 s and ending with a final $72{ }^{\circ} \mathrm{C}$ extension for 10 minutes. PCR products measuring $450 \mathrm{bp}$ were analyzed using electrophoresis gel agarose 1\%. Then HPV (Roche diagnostic) Probe Array (LPA) line was used to identify HPV genotype.

\section{Results}

Identification of HPV is done using the universal MY / GP primer, then a positive sample of HPV will produce a DNA tape size of $150 \mathrm{bp}$ on agarose gel. The results of HPV DNA isolation can be seen in Figure 1.
Data prevalence research samples from a total of 110 samples found 86 cases with positive HPV and 24 cases with negative HPV, or $78.2 \% \mathrm{HPV}$ positive and $21.8 \% \mathrm{HPV}$ negative.

The results of genotype analysis using specific primer to high-risk HPV, namely type $16,18,45,52,31$ and 33 , showed the distribution of HPV type 16 most of 42 cases (48.8\%), followed by HPV type 18 as many as 9 cases $(10.5 \%)$. Mixed types were found in 11 cases (12.8\%). No types 31 and 33 were found, as well as 23 cases $(26.7 \%)$ cannot be identified by type. The distribution data of HPV genotypes analysis can be seen in Figure 2.

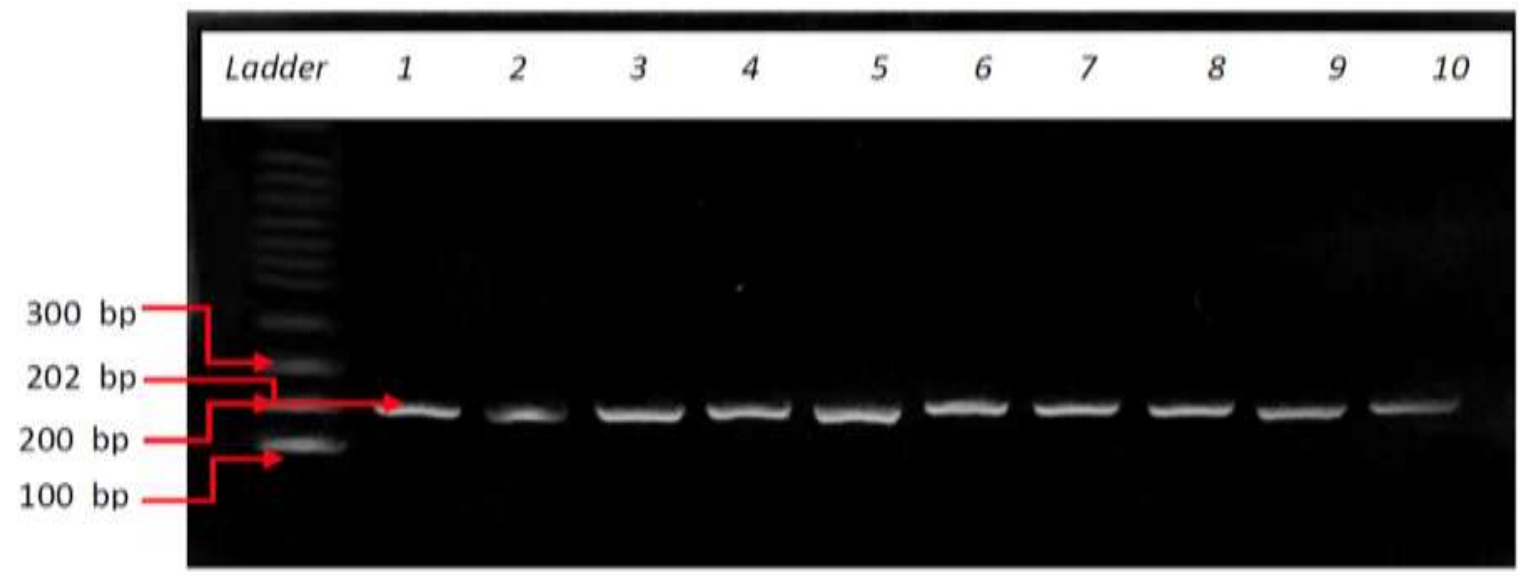

Fig. 1. Identify HPV DNA with my/GP universal primer with a $150 \mathrm{bp}$ DNA band. (A positive sample of HPV will produce a DNA tape size of $150 \mathrm{bp}$ on agarose gel.)

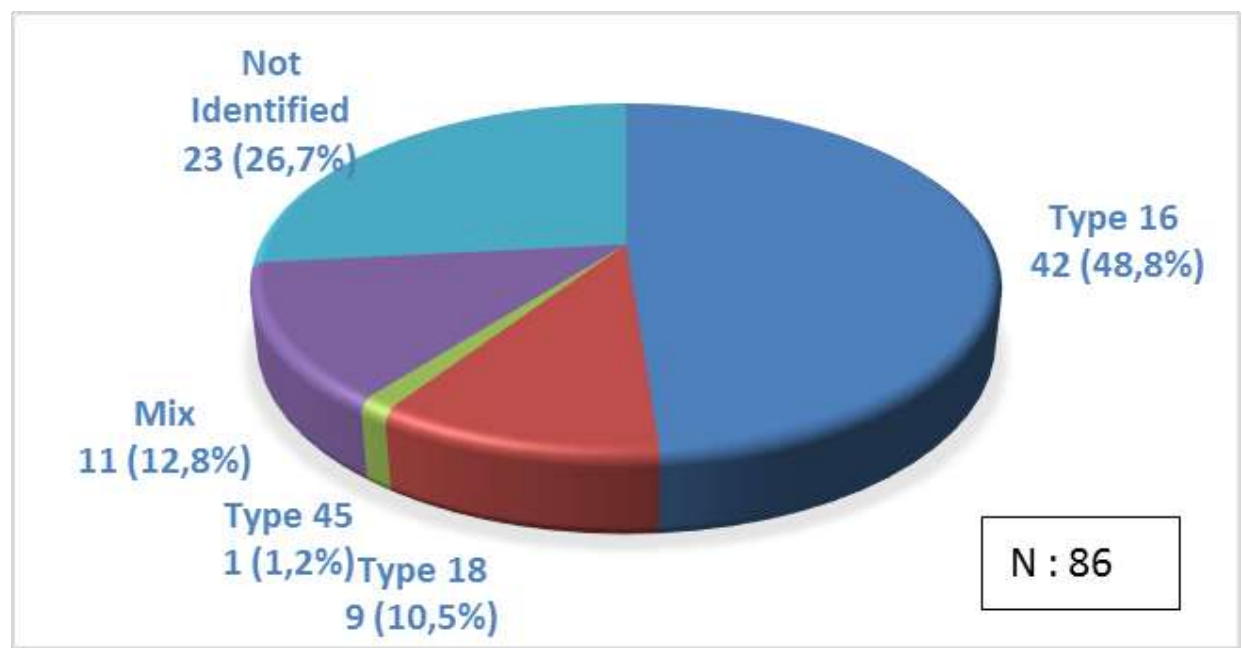

Fig. 2. Distribution of HPV in cervical cancer patients based on genotype analysis. Distribution of HPV type 16 most of cases (48.8\%), followed by HPV type 18 cases, and mixed types. 
Table 1 provides a distribution overview of samples characteristics in this study. Based on this table, it can be concluded that the average patient belonged to the age group of the early elderly. Most of the patient's parity status is multiparity. Meanwhile, only a small proportion of patients have other risk factors for cervical cancer such as multi-partner sex, smoking history, and IUD use.

Clinical manifestations were obtained from questionnaires that had been distributed to the participants when they were visiting Department of Obstetrics and Gynecology. The participants filled out a list of clinical manifestations that were felt when they came to the hospital. The distribution of clinical manifestations can be seen in Table 2. Based on table 2, the symptoms most frequently complained by all patients in this study were vaginal bleeding, fluor albus, fatigue and pelvic pain.

Table 1. Characteristics of subjects.

\begin{tabular}{lcc}
\hline \multicolumn{1}{c}{ Variable } & Mean \pm SD & N $(\%)$ \\
\hline Age (years) & $50 \pm 9.28$ & \\
Parity & $4.2 \pm 2.6$ & \\
Educational status & & \\
$\bullet \quad$ Elementary School - Junior High School & $71(64.5 \%)$ \\
$\bullet \quad \geq$ Senior High School & $39(35.5 \%)$ \\
Length of marriage & \\
$\bullet \quad<15$ years & $14(12.8 \%)$ \\
$\bullet \quad 15-20$ years & $71(64.5 \%)$ \\
- >20 years & $25(22.7 \%)$ \\
Sex partner (>1 person) & $16(14.5 \%)$ \\
History of smoking & $14(12.5 \%)$ \\
IUD (Intra Uterine Device) & $16(14.8 \%)$ \\
\hline
\end{tabular}

Table 2. Clinical manifestation of the subjects.

\begin{tabular}{cc}
\hline Description & $\mathbf{N}(\%)$ \\
\hline Vaginal bleeding & $80(72.7 \%)$ \\
Post coitus hemorrhage & $52(47.1 \%)$ \\
Post menopause hemorrhage & $48(43.2 \%)$ \\
Fluor Albus & $80(72.7 \%)$ \\
Pelvic pain & $66(60.2 \%)$ \\
Back pain & $50(45.5 \%)$ \\
Fatigue & $72(65.9 \%)$ \\
Leg pain & $28(25.5 \%)$ \\
Decreased appetite & $43(39.1 \%)$ \\
Limb edema & $9(8.2 \%)$ \\
Urine/stool leakage & $5(4.5 \%)$ \\
\hline
\end{tabular}




\section{Discussion}

The results showed 86 samples were HPV positive while 24 samples were negative. The results of genotype analysis are the highest distribution of HPV type 16 in 42 cases followed by HPV type 18 in 9 cases and HPV type 45 . These results are consistent with research in Manado. HPV type 16 ranks first as the most common cause of cervical cancer with a percentage of $76.36 \%$ (12). Langheden, 2018 found that most HPV cases are dominated by HPV type 16 by $60 \%$, followed by HPV 18 by $19 \%$, and other types total below $10 \%$ (13). Different results obtained by Zhang, where the most prevalent type was HPV -52 by $2,04 \%$ followed by HPV-16 by $1,81 \%$ (14).

Similar results were obtained by Awua who examined 256 patients with cervical cancer. A total of 230 patients were proven to have positive HPV with the typesfound were HPV18 (47.4\%), HPV59 (42.2\%), HPV45 $(37.4 \%)$ and HPV16 (9.0\%) (15). Volpini also detected variations in the type of high risk HPV with the highest prevalence being in HPV types $16(8.9 \%)$ followed by HPV types 45 and 18 with values of $6.7 \%$ and $4.4 \%$ (16).

The results of this study show that the average patient belonged to the age group of the early elderly. The same results were obtained from studies conducted in Turkey by Boyraz on 126 cervical cancer patients with an average age of 52 years in the range of 29-83 years (17). But it is different from studies conducted on 524 women in Puerto Rico, where the most age is less than 35 years (18).

The level of education is closely related to public awareness to get treatment from medical personnel. The results showed the majority of patients with low education, one level below senior high school. The level of education also affects personal hygiene behavior. This is in line with systematic review research by Lim, J in Sub Saharan Africa states that poor knowledge of cervical cancer becomes a major personal obstacle to cervical screening and becomes an obstacle for women to prevent cervical cancer (19).

In this study it was seen that women who have sexual relations under 20 years are quite dominant in relation to cervical cancer. Research conducted by Mitiku found that the incidence of cervical cancer is strongly associated with sexual behavior, such as multiple sexual partners and age during sexual intercourse. The risk of suffering from cervical cancer increases more than 6 times in women who have sexual contact at the age of $<20$ years \{Formatting Citation\}. In this study, the average woman gave birth 4 times, with a range of 2-6 times.

Another study conducted by Setyarini found that women with> 3 times parital status have 5 times risk of suffering from cervical cancer (21). Parity is an extrinsic factor that is closely related to an increased risk of cervical cancer. Let alone, if the time interval between labor is too close. The possible connection is that hormonal factors during pregnancy that facilitate the development of cancer cells. In pregnant women, there will be a process of uterine cervical cell metaplasia and low immune power of pregnant women due to the process during childbirth. But women with parity 0 and parity> 5 also have cervical cancer. This indicates that parity is not the only cause of cervical cancer \{Formatting Citation .

In 2015, Liu Chang conducted an analysis that looked at the correlation between multiple sexual partners and the incidence of cervical cancer. The results showed that women who had 4-7 sexual partners had a risk of developing cervical cancer whether or not the HPV virus was detected (23). The incidence of cervical cancer is associated with transmission from men (24).

In this study, showed that 16 patients had more than 1 sexual partners. This was probably due to the culture of Indonesian people who still considered changing partners as an act that violated the norms in society. Other risk factors derived from this study were smoking history and IUD use. Research by Zidi et al says that smoking is the most significant environmental risk factor for cervical cancer. It is associated with the chemical carcinogen benzopyrene contained in cigarettes is shown 
to increase the synthesis of HPV in cervical cells and cause viral persistence in many cases (25) Other studies said that long-term hormonal use with CIN 2/3 cervical cancer risk has a positive relationship (26).

Based on the results, one of the symptoms most frequently complained by all patients in this study is vaginal bleeding. Vaginal bleeding is the cause of death by $6 \%$ in cases of cervical cancer. The incidence varies from $0.7 \%-100 \%$ and the treatment faces many challenges (27).

Other symptoms like weight loss, fatigue, and lack of appetite are common symptoms experienced by cancer patients, including cervical cancer.

The presence of fistulas in the form of leaking urine / feces is a rare form of complications from the course of cervical cancer. This fistula if left unchecked will cause a continuous discharge of fluid from the vagina. Surgery is the most effective option for repairing the fistula. In some cases, treatment also includes giving a cream or ointment to reduce fluid coming out of the vagina and prevent irritation and tissue damage to the vagina and surrounding tissue. There were also

\section{References}

1. Bray F, Ferlay J, Soerjomataram I, Siegel RL, Torre LA, Jemal A. Global cancer statistics 2018: GLOBOCAN estimates of incidence and mortality worldwide for 36 cancers in 185 countries. CA Cancer J Clin. 2018;68(6):394-424.

2. Manga MM, Fowotade A, Abdullahi YM, ElNafaty AU, Adamu DB, Pindiga HU, et al. Epidemiological patterns of cervical human papillomavirus infection among women presenting for cervical cancer screening in North-Eastern Nigeria. Infect Agent Cancer. 2015;10:39.

3. Nurcahyanti AD. Cervical Cancer: The Case in Indonesia and Natural Product- Based Therapy. J Cancer Biol Res. 2016;4(1):1078.

4. Rezai M, Saravani R, Sargazi S, Moudi M, Jafari Shahroudi M, Saravani R. Achillea Wilhelmsii C. Koch Hydroalcoholic Extract Induces Apoptosis and Alters LIN28B and p53 Gene Expression in Hela Cervical Cancer Cells. Rep Biochem Mol Biol. 2019;8(3):318-325. about $4.5 \%$ of patients in this study who experienced leakage of urine / feces.

This study shows out of 110 women, 86 (78.1\%) were found HPV positive, and the most common HPV genotype in Pekanbaru is HPV type 16 (48.8\%). Besides that, the most common clinical symptoms of cervical cancer patient are vaginal bleeding, fluor albus, pelvic pain and fatigue.

\section{Acknowledgements}

The authors would like to thank the Department of Obstetrics and Gynecology Arifin Achmad General Hospital Riau, Microbiology Department, Faculty of Medicine University of Riau, and Faculty of Medicine Andalas University for the opportunity to give permission to the authors to research.

This work was supported by Ministry of Research, Technology, and Higher Education of Republic Indonesia, Institutions and Community Service of Universitas Riau with number 276/UN.19.5.1.3/PP/2018. The role of the funder is to provide funding needed during the research conducted by the researcher.

5. Wang KL Human Papillomavirus and Vaccination in Cervical Cancer. Taiwan J Obstet Gynecol. 2007;46(4): 352-362.

6. Bruni L, Barrionuevo-Rosas L, Serrano B, Gomez D, Munoz J, Bosch F, et al. Human papillomavirus and Related diseases report in Indonesia. ICO Inf Cent HPV Cancer. 2017.

7. Pan J, Kavanagh K, Cuschieri K, Pollock KG, Gilbert DC, Millan D, et al. Increased risk of HPVassociated genital cancers in men and women as a consequence of pre-invasive disease. Int J Cancer. 2019;145(2):427-434.

8. Kovacevic G, Milosevic V, Knezevic P, Knezevic A, Knezevic I, Radovanov J, et al. Prevalence of oncogenic Human papillomavirus and genetic diversity in the L1 gene of HPV16 HPV 18 HPV31 and HPV33 found in women from Vojvodina Province Serbia. Biologicals. 2019;58:57-63.

9. Lipinwati. Molecular Diagnosis of Human 
Papilloma Virus (HPV) Causes Cervical Cancer Lipinwati. Jambi Med J. 2014;2(1):78-86.

10. Chiang YC, Chen YY, Hsieh SF, Chiang CJ, You SL, Cheng WF, et al. Screening frequency and histologic type influence the efficacy of cervical cancer screening: A nationwide cohort study. Taiwan J Obstet Gynecol. 2017;56(4):442-448.

11. Stapley S, Hamilton W. Gynaecological symptoms reported by young women: examining the potential for earlier diagnosis of cervical cancer. Family Practice. 2011;28(6):592-598.

12. Mongan SP, Andrijono Andrijono, Tjahadi $\mathrm{H}$. Obstet Gynecol Human Papilloma Virus L1 Gene Methylation as a Potential Biomarker for Precancerous Cervical Lesion: a Preliminary Report Human Papilloma Virus L1 Gene Methylation as a Potential Biomarker for Precancerous Cervical Lesions: A Preliminary Report. Indones Obstet Gynecol 2017;5-2. 120-126.

13. Lagheden C, Eklund C, Lamin H, Kleppe SN, Lei J, Elfström KM, et al. Nationwide comprehensive human papillomavirus (HPV) genotyping of invasive cervical cancer. british journal of cancer. 2018;118(10):1377-81.

14. Wang Y, Wang S, Shen J, Peng Y, Chen L, Mai $\mathrm{R}$, et al. Genotype Distribution of Human Papillomavirus among Women with Cervical Cytological Abnormalities or Invasive Squamous Cell Carcinoma in a High-Incidence Area of Esophageal Carcinoma in China. Biomed Res Int. 2016;2016:1256384.

15. Awua AK, Sackey ST, Osei YD, Asmah RH, Wiredu EK. Prevalence of human papillomavirus genotypes among women with cervical cancer in Ghana. Infect Agent Cancer. 2016;11:4.

16. Volpini LPB, Boldrini NAT, de Freitas LB, Miranda AE, Spano LC. The high prevalence of HPV and HPV16 European variants in cervical and anal samples of HIV-seropositive women with normal Pap test results. PLoS One. 2017;12(4):e0176422.

17. Boyraz G, Basaran D, Salman MC, Ozgul N, Yuce K. Clinical and pathological characteristics related to parametrial involvement in clinical earlystage cervical cancer. Ginekol Pol. 2016;87(6):41721.

18. Pérez-Caraballo AM, Suarez E, Unger ER, Palefsky JM, Panicker G, Ortiz AP. Seroprevalence of human papillomavirus (Hpv) type 6, 11, 16, 18, by anatomic site of hpv infection, in women aged 16-64 years living in the metropolitan area of San Juan, Puerto Rico. P R Health Sci J. 2018;37(1):2631.

19. Lim JNW, Ojo AA. Barriers to utilisation of cervical cancer screening in Sub Sahara Africa: a systematic review. Eur J Cancer Care (Engl). 2017;26(1).

20. Mitiku I, Tefera F. Knowledge about cervical cancer and associated factors among 15-49 year old women in dessie town, northeast ethiopia. PLoS One. 2016;11(9):e0163136.

21. Setyarini E. Factors Associated with the Incidence of Cervical Cancer in RSUD Dr. Moewardi Surakarta. Univ Muhammadiyah Surakarta. 2019.

22. Haryani S, Defrin D, Yenita Y. Cervical Cancer Prevalence Based on Parity in RSUP. Dr. M. Djamil Padang Period January 2011-December 2012. Andalas Medical Journal. 2016 Sep 1;5(3).

23. Liu Y, Xin H, Xu S, Qu J, Wang Y, DiaoX-Li, et al. Epidemiology and genotype distribution of high risk human papillomavirus in population of hospital opportunistic screening. Int J Clin Exp Med. 2015;8(9):16007-16014.

24. Morris BJ, Hankins CA, Banerjee J, Lumbers ER, Mindel A, Klausner JD, et al. Does male circumcision reduce women's risk of sexually transmitted infections, cervical cancer, and associated conditions? Front Public Health. 2019;7:4.

25. Zidi S, Sahli M, Mezlini A, Yacoubli-Loueslati B. Association of Combined Tobacco Smoking, Hormonal Contraceptive use and Status Matrimonial with Cervical Cancer Evolution in Tunisian Women. Pathol Oncol Res. 2020;26(1):217-222.

26. Oh HY, Kim MK, Seo SS, Lee JK. Association of combined tobacco smoking and oral contraceptive use with cervical intraepithelial neoplasia 2 or 3 in Korean women. J Epidemiol. 2016;26(1):22-29.

27. Eleje GU, Eke AC, Igberase GO, Igwegbe AO, Eleje LI. Palliative interventions for controlling vaginal bleeding in advanced cervical cancer. Cochrane Database Syst Rev. 2015(5):CD011000. 